\title{
PREPARATION OF Cu(110)-Fe ALLOYS AND THEIR REACTIVITY TOWARDS OXYGEN
}

\author{
Olaf P. VAN PRUISSEN, Gerrit C. VAN LEERDAM, \\ Onno L.J. GIJZEMAN and John W. GEUS \\ Van 't Hoff Laboratory, University of Utrecht. Padualaan $8,3584 \mathrm{CH}$ Utrecht. The Netherlands
}

Received 10 February 1987; accepted for publication 11 April 1987

$\mathrm{Cu}(110)-\mathrm{Fe}$ alloys are prepared by thermal decomposition of $\mathrm{Fe}(\mathrm{CO})_{5}$ at $600 \mathrm{~K}$. Iron facets grow under an inclination angle of $35.2^{\circ}$ with the surface exposing a (110) plane. The majority of iron is distributed below the surface layer and there is hardly any enrichment of copper at the surface layer. Oxygen adsorption is not noticably accelerated compared to that on $\mathrm{Cu}(110)$. At temperatures below $400 \mathrm{~K}$ even a decrease in sticking coefficient is noticed. The total oxygen uptake increases with temperature and iron content.

\section{Introduction}

Bimetallic systems are known to differ in electronic structure from bulk materials and may therefore alter some specific catalytic properties. To tailor a new catalyst in the synthetic fuel industry the use of copper alloyed with iron seems promising.

The two issues of this study are the deposition of iron by thermal decomposition of iron carbonyl on $\mathrm{Cu}(110)$ and the reactivity of a thus prepared crystal with oxygen. 'The deposition of iron and oxidation can be followed in-situ continuously with ellipsometry or, after successive gas exposures, with Auger spectroscopy. Afterwards characterization of the surface with LEED is possible.

\section{Experimental}

The experiments were performed in a standard UHV system with facilities for ellipsometry, Auger electron spectroscopy (AES) and low energy electron diffraction (LEED) [1]. For the technical data - the recording of the Auger spectra with a four-grid retarding field analyser, the automatic nulling ellipsometer and the preparation of iron carbonyl - we refer to ref. [2].

The crystal was disk-shaped (diameter $10 \mathrm{~mm}$ ), spark-cut from a $5 \mathrm{~N}$ copper

0169-4332/87/\$03.50 Elsevier Science Publishers B.V.

(North-Holland Physics Publishing Division) 
rod to within $\pm 1^{\circ}$ of the (110) orientation. The crystal was cleaned by sputtering and annealing. Normally the sputtering procedure was applied at $400 \mathrm{~K}\left(450 \mathrm{eV}, 500 \mathrm{nA} \mathrm{cm}{ }^{-2}, 10^{-2} \mathrm{~Pa} \mathrm{Ar}\right)$ when only iron was deposited. When the crystal was oxidized thoroughly the crystal was sputtered at $725 \mathrm{~K}$. Due to the presence of $\mathrm{Fe}_{0.95} \mathrm{O}$ [5] both the iron and oxygen segregate to the surface and this caused the total sputtering time to decrease by a factor of about five. The annealing temperature was $725 \mathrm{~K}$. The $\mathrm{Cu}(110)-\mathrm{Fe}$ alloys were prepared by thermal decomposition of iron carbonyl, $\mathrm{Fe}(\mathrm{CO})_{5}$.

From the high energy part of the Auger spectrum $(630-940 \mathrm{eV})$ the amount of iron in the first 6-8 atomic layers can be calculated with:

$x_{\mathrm{H}}(\mathrm{Fe})=0.8 h_{651} /\left(0.8 h_{651}+h_{920}\right)$,

where $h_{651}$ is the peak-to-peak height of the Fe $651 \mathrm{eV}$ signal and $h_{920}$ is the height of the $\mathrm{Cu} 920 \mathrm{eV}$ signal. From the low energy part of the spectrum $(30-65 \mathrm{eV})$ the amount of iron in the first 2-3 atomic layers can be calculated with:

$x_{\mathrm{L}}(\mathrm{Fe})=0.8 h_{47} /\left(0.8 h_{47}+h_{61}\right)$,

where $h_{47}$ is the height of the $\mathrm{Fe} 47 \mathrm{eV}$ signal and $h_{61}$ is the height of the $\mathrm{Cu}$ $61 \mathrm{eV}$ signal. The sensitivity factor of 0.8 was taken from ref. [2].

The absolute coverage determination of oxygen $\theta_{\mathrm{O}}$ is based on the occurrence of a $(2 \times 1)$ LEED pattern which is equivalent to $\theta_{\mathrm{O}}=0.5[3,4]$. The absolute carbon coverage is determined as in ref. [2].

\section{Results}

\subsection{Deposition of iron on $\mathrm{Cu}(110)$}

Iron was deposited on $\mathrm{Cu}(110)$ by thermal decomposition of $\mathrm{Fe}(\mathrm{CO})_{5}$ at $600 \mathrm{~K}$. Fig. 1 shows the change of $\Delta$ and $\psi$ during deposition. The horizontal axis is given in arbitrary units as the composition of the gas mixture is unknown and so is the carbonyl exposure; an average exposure of the gas mixture to change $\psi$ by $0.1^{\circ}$ is about $5 \mathrm{~Pa}$ s. In fig. 1 also the changes of $\psi$ and $\Delta$ during deposition of iron on $\mathrm{Cu}(111)$ are shown [2]. The increase of $\Delta$ during deposition of iron on $\mathrm{Cu}(110)$ is huge in comparison with the one observed for $\mathrm{Cu}(111)$ and also with those observed during the deposition of nickel on the three low-index planes of copper $[2,6]$.

As $\delta \psi$ appeared to be a good monitor for the amount of iron deposited on $\mathrm{Cu}(111)$ [2], the iron mole fraction $x_{\mathrm{H}}(\mathrm{Fe})$ was measured as a function of the amount of iron deposited as given by $\delta \psi$ (fig. 2). As can be seen $x_{\mathrm{H}}(\mathrm{Fe})$ increases almost linearly with $\delta \psi$ and thus parallels the behaviour noticed on $\mathrm{Cu}(111)$. The mole fraction in the outer two layers $x_{\mathrm{L}}(\mathrm{Fe})$ was about 0.10 less 


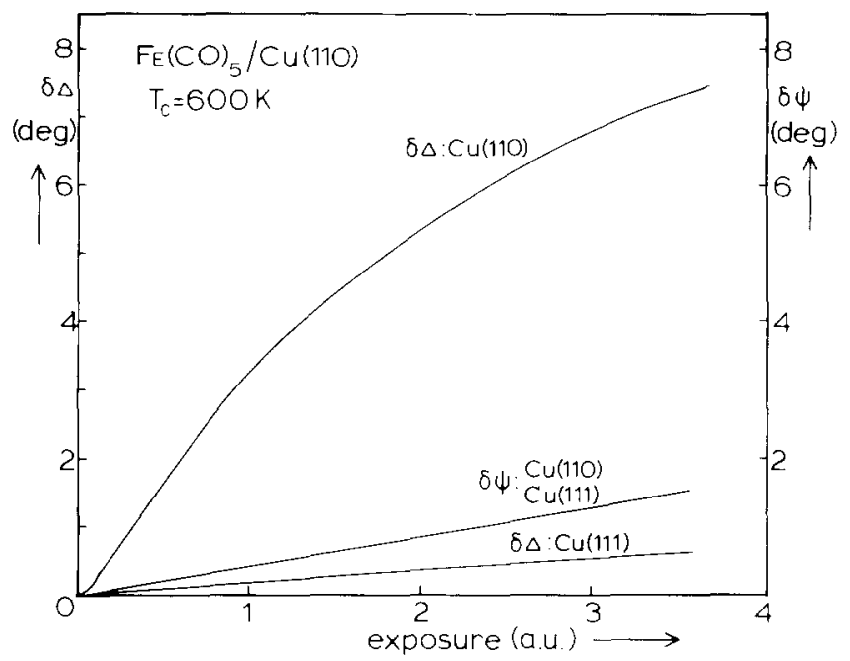

Fig. 1. Dependence of $\delta \Delta$ and $\delta \psi$ on iron carbonyl exposure at $600 \mathrm{~K}$.

than $x_{\mathrm{H}}(\mathrm{Fe})$. The annealing time (at $725 \mathrm{~K}$ ) before exposure to $\mathrm{Fe}(\mathrm{CO})_{5}$ was varied and chosen to be 30 or $10 \mathrm{~min}$. It appears that in the latter case iron penetrated deeper into the crystal as less iron is observed near the surface.

Fig. 3 shows the influence of sputtering on the composition of such a crystal. The amount of iron decreases smoothly with time, although initially it remains constant.

After deposition of small amounts of iron $\left(\delta \psi_{\mathrm{Fe}}<0.2^{\circ}\right)$ no oxygen and

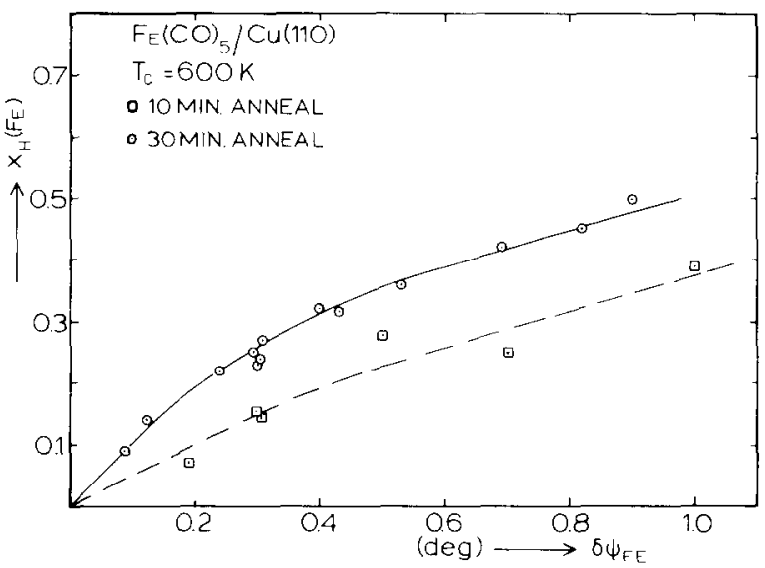

Fig. 2. Iron mole fraction in the outer 6-8 layers as a function of the amount of iron deposited. denoted as $\delta \psi_{\mathrm{Fe}}$. 


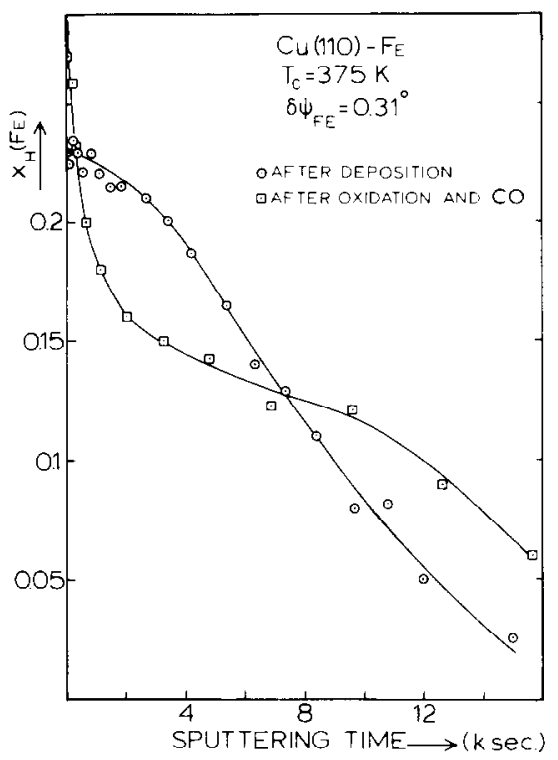

Fig. 3. Sputter profile of $\mathrm{Cu}(110)-\mathrm{Fe}$ crystals after preparation at $600 \mathrm{~K}$ and after oxidation and CO-reduction at $525 \mathrm{~K}$.

carbon are observed at the surface, at larger amounts of iron both elements are detected (although more oxygen than carbon). The amounts increase with increasing iron content.

After iron deposition the surface was studied with LEED.

Fig. 4b shows a pattern observed at an electron energy of $135 \mathrm{eV}$. More spots are visible than only those due to $\mathrm{Cu}(110)$, the extra ones located in the $\langle 100\rangle$ rows. At other energies extra spots in the $\langle 100\rangle$ rows are also observed but at different positions, obviously the diffracted LEED beams do not simply converge in the specular direction. It appears that as a function of the energy some spots move in the $\langle 100\rangle$, others in the $\langle\overline{100}\rangle$ direction. The extra spots are seen when more iron is deposited than corresponding to $x_{\mathrm{H}}(\mathrm{Fe})=0.15$. At large iron content more but very vague spots are observed and not only in the $\langle 100\rangle$ rows.

\subsection{Oxidation of $\mathrm{Cu}(110)-\mathrm{Fe}$}

Oxygen was exposed to $\mathrm{Cu}(110)-\mathrm{Fe}$ surfaces containing different amounts of iron at pressures ranging from $10^{-6}$ to $10^{-4} \mathrm{~Pa} \mathrm{O}_{2}$ and crystal temperatures from 300-575 K. The oxidation process was studied with AES and ellipsometry. The results of the latter technique, however, are difficult to interpret. Depending on the amount of iron present in the crystal and the 

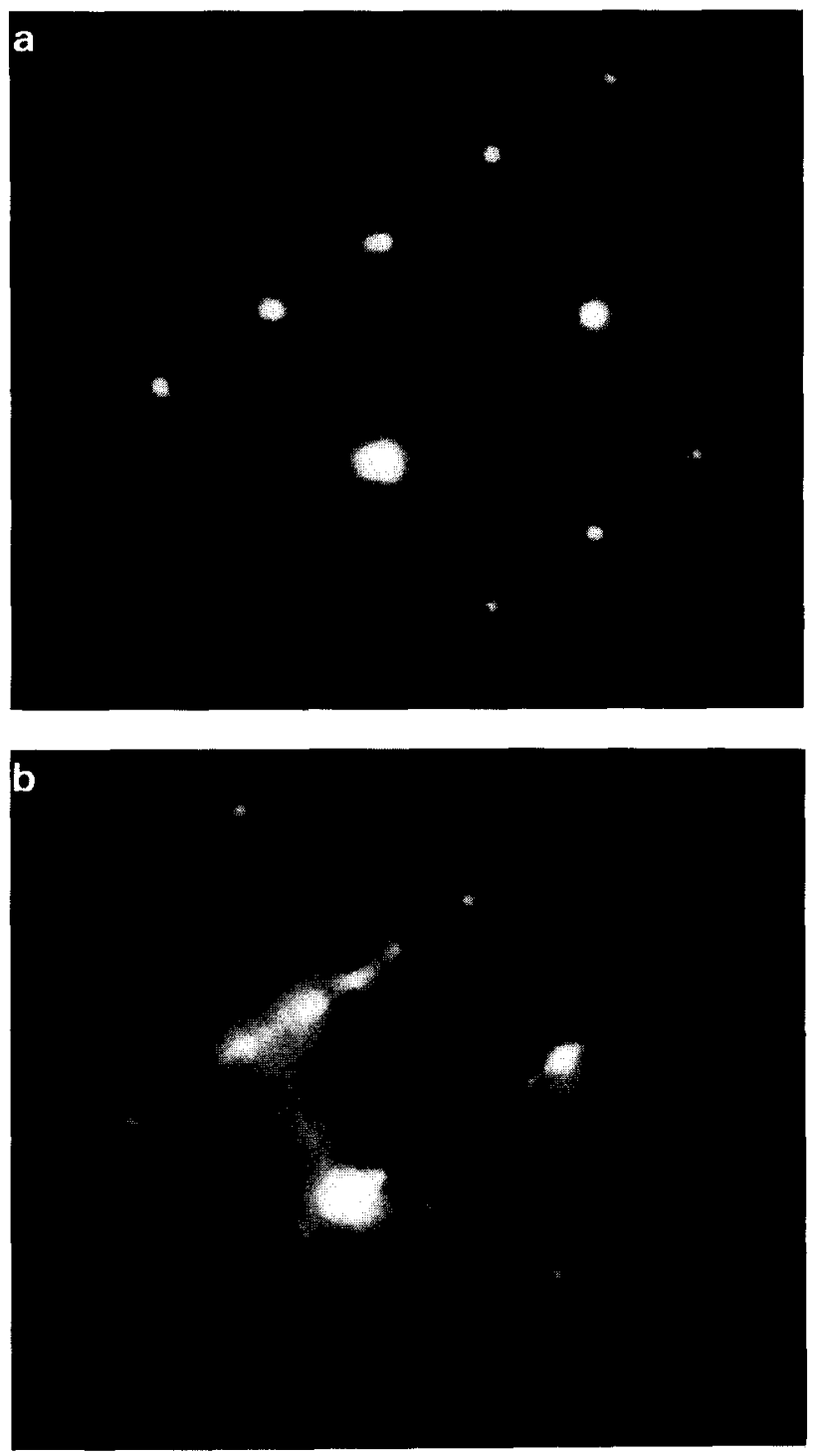

Fig. 4. LEED patterns of (a) clean $\mathrm{Cu}(110)$ and (b) $\mathrm{Cu}(110)-\mathrm{Fe}$ with an amount of iron corresponding to $\delta \psi_{F_{e}}=0.3^{\circ}$. $E_{\text {clectron }}=135 \mathrm{eV}$.

crystal temperature, the variation of $\delta \Delta$ was unusual. At temperatures higher than $500 \mathrm{~K}$ even a decrease in $\delta \Delta$ was observed, which should be ascribed to oxygen removal rather than an increase in oxygen coverage. At these temperatures $\delta \Delta$ reached a minimum, which was more than $1.0^{\circ}$ below the initial 


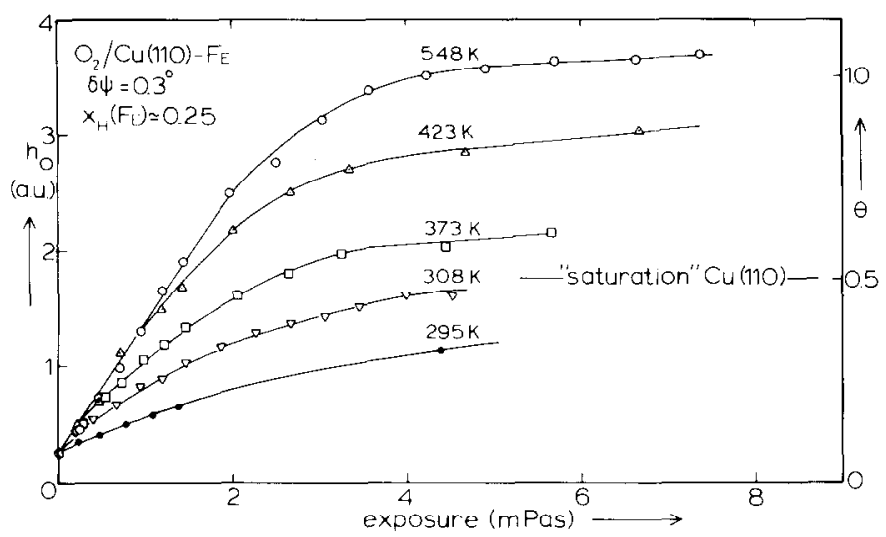

Fig. 5. Dependence of the oxygen AES peak on the oxygen exposure of a $\mathrm{Cu}(110)-\mathrm{Fe}$ crystal. Initial rate of oxygen uptake of pure $\mathrm{Cu}(110)$ is equal to those measured at 423 and $548 \mathrm{~K}$ but starts at $h_{\mathrm{O}}=0$. Lines are drawn to guide the eye.

value, after which $\delta \Delta$ increased, although its final saturation value was still negative. Therefore, only the AES results will be presented here, which are obtained by interrupted exposure of oxygen.

The oxidation of a $\mathrm{Cu}(110)-\mathrm{Fe}$ surface corresponding to $\delta \psi_{\mathrm{Fe}}=0.3^{\circ}$ with an iron content of $x_{\mathrm{H}}(\mathrm{Fe}) \cong 0.25$ was studied at different crystal temperatures. In fig. 5 the oxygen Auger signal $h_{\mathrm{O}}$ is depicted as a function of the oxygen exposure. Normalization of this signal to the copper signal has not been performed as we wish to compare the present results to those for pure $\mathrm{Cu}(110)$, where the copper peak is larger since no iron is present. From oxidations of pure $\mathrm{Cu}(110)$ and the occurrence of a LEED $(2 \times 1)$ pattern $[3,6]$ the following equation was derived for our system:

$\theta_{\mathrm{O}}=1.0 h_{\mathrm{O}} / h_{\mathrm{Cu}}$.

Up to $395 \mathrm{~K}$ the initial rate of change of $h_{\mathrm{O}}$ increases with increasing temperature, whereas at higher temperatures it remains constant. Upon further oxygen adsorption the rate of change of $h_{\mathrm{O}}$ decreases, but up to exposures of $100 \mathrm{mPa} s$ no saturation can be observed. At increasing temperature more oxygen can be accommodated into the crystal before the rate of change drops. After $2 \mathrm{mPa} s$ spots of a $(2 \times 1)$ LEED pattern can be observed, while at about $100 \mathrm{mPa} s$ especially after exposure at high temperatures, a $\mathrm{c}(6 \times 2)$ superstructure is visible. During the oxygen adsorption the iron fraction $x_{\mathbf{H}}(\mathrm{Fe})$ remains constant at temperatures below $500 \mathrm{~K}$. At higher temperatures $x_{\mathrm{H}}(\mathrm{Fe})$ increases to $140 \%$ of its initial value at an exposure of $2.5 \mathrm{mPa}$ s after which $x_{\mathrm{H}}(\mathrm{Fe})$ decreases to about 0.30 at higher exposures.

In addition the oxidation of $\mathrm{Cu}(110)-\mathrm{Fe}$ surfaces containing different 


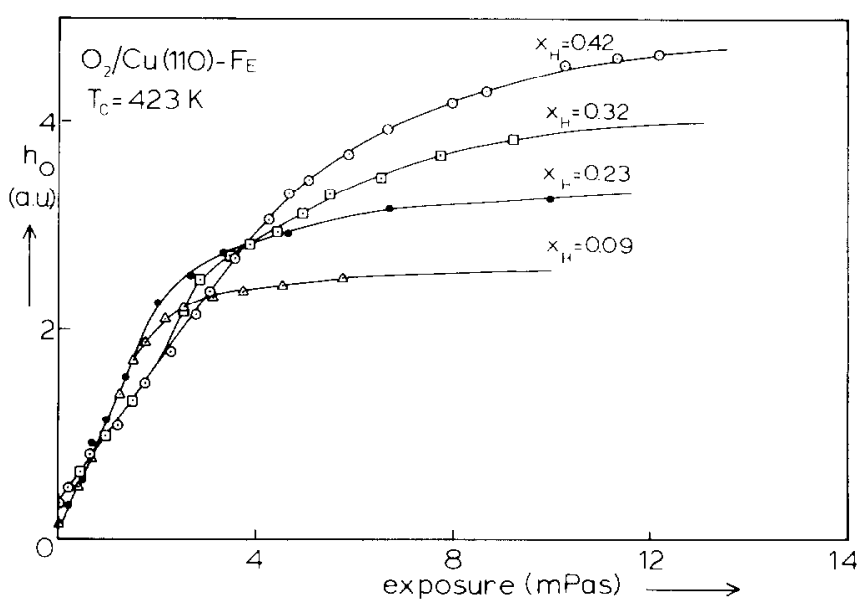

Fig. 6. Dependence of the oxygen AES peak on the oxygen exposure of $\mathrm{Cu}(110)$-Fe crystals containing different amounts of iron at $423 \mathrm{~K}$. Lines are drawn to guide the eye.

amounts of iron was studied at a crystal temperature of $423 \mathrm{~K}$. From fig. 6 it can be seen that at small iron fractions $\left(x_{\mathrm{H}}(\mathrm{Fe})<0.25\right)$ the initial rate of change of $h_{\mathrm{O}}$ is larger than for crystals containing more iron. At increasing iron fractions more oxygen can be adsorbed.

Already during the initial stage of the oxidation the $h_{47}$ peak vanishes in favour of the $h_{44}$ peak which shows that iron is oxidized immediately. After completed oxidation at $300<T_{\mathrm{c}}<500 \mathrm{~K}$ the low energy iron peak $h_{47}$ has disappeared, in favour of two peaks at 44 and $51 \mathrm{eV}$, well known for oxidized iron.

Heating the crystal to $675 \mathrm{~K}$ causes $h_{47}$ to reappear in addition to the other peaks (fig. 7 ); $h_{651}$ shows a very large increase as well. After a next oxidation at $675 \mathrm{~K}$ the $h_{651}$ peak had reduced to its original value and only the $h_{44}$ and $h_{51}$ peaks were observed.

To investigate some thermodynamic aspects the crystals were subsequently oxidized until saturation - saturation being defined as a change of $\Delta$ less than $0.01^{\circ}$ after $10 \mathrm{mPa} \mathrm{s}$ - at $300,425,600$ and $675 \mathrm{~K}$. After completion of this routine it was observed that, independent of the original amount of iron, the final iron mole fraction always yielded $x_{\mathrm{H}}=0.18-0.25$ (fig. 8), except when very small amounts of iron were deposited $\left(\delta \psi_{\mathrm{Fe}}<0.2^{\circ}\right)$. After this pretreatment and a reduction by $\mathrm{CO}$ at $525 \mathrm{~K}$ lcaving a bare copper surface and an undisturbed iron-oxide surface [5] a crystal was sputtered. Fig. 3 shows the iron profile thus obtained. When the sputtering was interrupted for $16 \mathrm{~h}$ the iron and copper signals did not change. As can be seen, on the one hand some iron is attracted to the surface while on the other some has migrated deeper into the surface. Since an equal amount of iron was deposited when no 


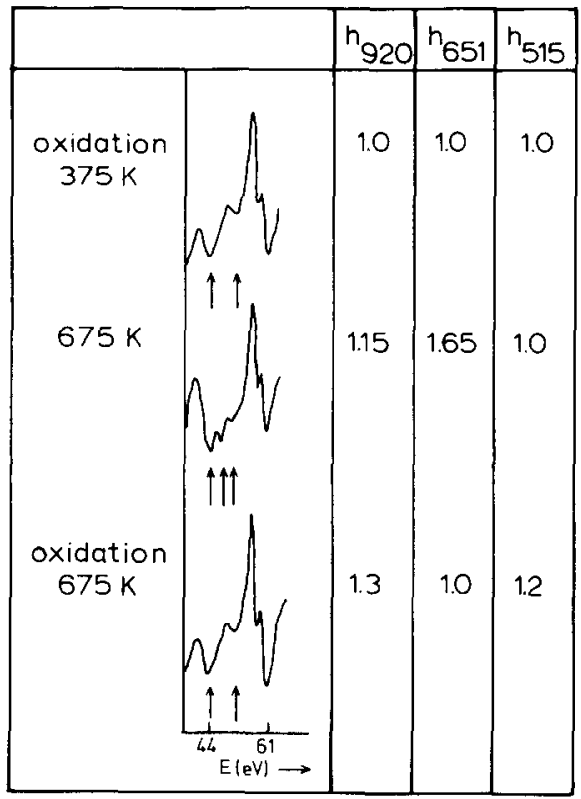

Fig. 7. The AES $h_{920}, h_{651}$ and $h_{515}$ peak heights - normalized to their initial values - and the AES spectrum from 30 to $65 \mathrm{eV}$ after oxidation at $375 \mathrm{~K}$, subsequent heating to $675 \mathrm{~K}$ and a consecutive oxidation at $675 \mathrm{~K}$.

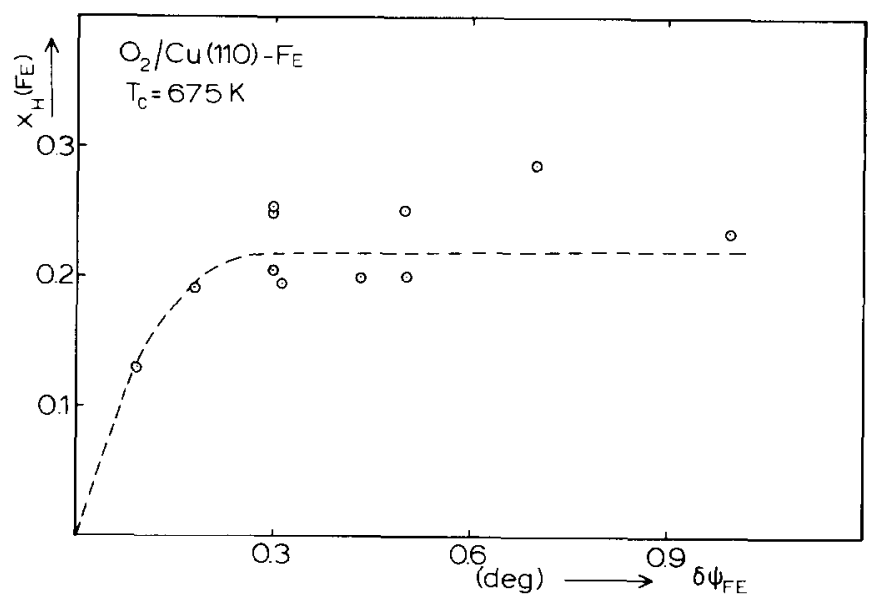

Fig. 8. Iron mole fraction $x_{\mathrm{H}}(\mathrm{Fe})$ after oxidation at $675 \mathrm{~K}$, after being oxidized before at 300,425 and $600 \mathrm{~K}$, as a function of the amount of deposited iron. 
oxidation was performed and the areas underneath the sputter curves were almost equal, differences in sputter efficiency are small. Up to $7 \mathrm{ks}$ of sputtering the oxygen/iron ratio $h_{\mathrm{O}} / h_{\mathrm{Fe}}$ was constant and about equal to 3.5 .

\section{Discussion}

\subsection{Growth of iron on $\mathrm{Cu}(110)$}

After deposition of iron another LEED pattern is observed, though all original spots of $\mathrm{Cu}(110)$ remain visible. Since the solubility of iron in copper is extremely low [7,8] and also clustering of $\mathrm{Fe}$ on $\mathrm{Cu}(111)$ was observed [9], it is assumed that the extra spots originate from pure iron crystallites. The spots moving along the $\langle 100\rangle$ rows indicate that iron planes develop which are inclined relative to the original surface. The edges at which the facets touch each other are parallel to the 011$\rangle$ direction. It also implies the same interatomic distance for iron $(2.55 \AA)$ as for copper in a certain, yet not specified, direction. To determine the angle of inclination of the facets a procedure was followed first described by Tucker [10]. He derived an equation which describes the movement of spots accross the $(0,0)_{C u}$ beam;

$\mathrm{d} \lambda / \mathrm{d} \phi=\frac{1}{2} \lambda \cot \alpha$,

where $\lambda$ is the wavelength of an incident electron, $\phi$ is the angle of an electron diffracted by a facet with respect to the $(0,0)_{\mathrm{Cu}}$ beam and $\alpha$ the angle of inclination. Applying this relation to beams crossing the $(0,0)_{\mathrm{Cu}}$ beam at $102 \pm 2$ and $207 \pm 3 \mathrm{eV}$ a value for $\alpha$ was found of $35 \pm 1^{\circ}$. To determine the scattering distance in the $\langle 100\rangle$ direction, $d_{\mathrm{Fe}}$, a relation was used given by Ertl and Küppers [11]:

$\Delta n / \Delta(1 / \lambda)=2 d_{\mathrm{Fc}} \sin \phi$,

where $n$ is the number of spots which passed the $(0,0)_{\mathrm{Cu}}$ beam. Thus it follows that $d_{\mathrm{Fe}}=2.5 \pm 0.1 \AA$. So in both scattering directions the scattering distances are equal within experimental error. This is confirmed by the LEED pattern from the spots moving in one identical direction only. From these patterns it follows that there is an angle of about $60^{\circ}$ between the two hasis vectors, which suggests that $\mathrm{Fe}(110)$ facets are formed. Since $\mathrm{Cu}(111)$ planes are inclined $35.2^{\circ}$ relative to the $\mathrm{Cu}(110)$ plane and these planes resemble $\mathrm{Fe}(110)$ planes much, this geometrical configuration can be advantageous for iron. It is noteworthy that an Fe atom in a facet possesses precisely half the unit area of a $\mathrm{Cu}$ atom when projected on the original surface.

Up till here proof lacks that the facets are composed of $\mathrm{Fe}$ and not of $\mathrm{Cu}$. To investigate this the following measurement was performed. After deposition of iron the crystal was rotated along the vertical axis of the sample holder 


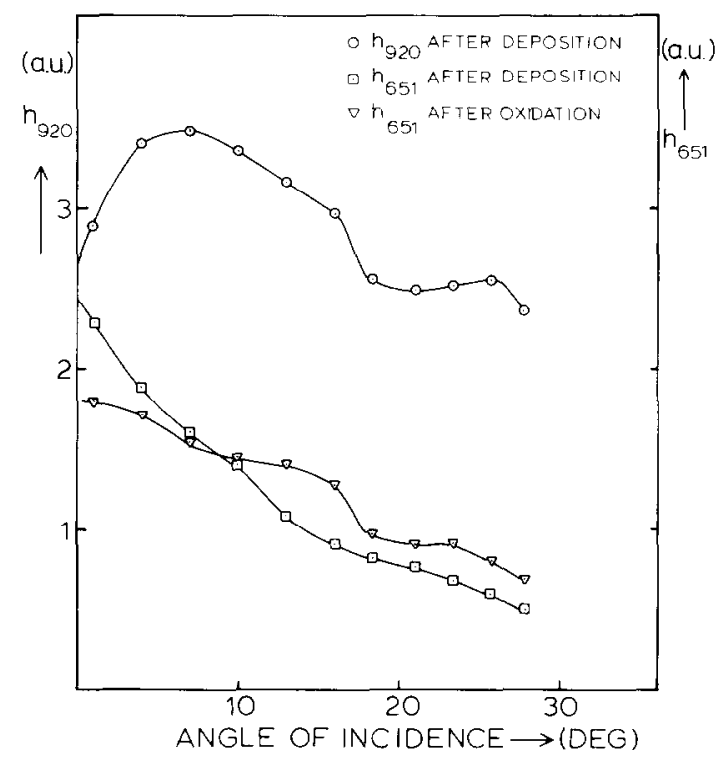

Fig. 9. The AES $h_{920}$ and $h_{651}$ peaks as a function of the angle of electron incidence after iron deposition and after subsequent oxidation.

[1] and the $h_{651}$ and $h_{920}$ signals were recorded. From this angle the angle of incidence of the electron beam was calculated and the signals were analysed. Of course we admit that this procedure is subject to criticism since our detection system should be rotated as well, but for our modest purposes the experimental set-up is satisfactory. In fig. 9 the results are given. At an angle of $0^{\circ}$ the incident electrons can only touch the edge of the crystal (i.e. the elevation angle is $90^{\circ}$ ). Remarkably, at high angles of elevation relatively much iron is observed in comparison to copper. There are two alternative assumptions explaining this observation. The first is that since the facets of iron point out of the copper surface hardly any incident electron can excite a copper atom since at these angles the facets block the copper surface. The second is that as Auger electrons can escape only from the outer surface layers it must simply be ascribed to an enrichment of iron in this region. This second explanation must be discarded, examining the results of the same experiment done on an oxidized, not facetted surface [5]. From fig. 3 it is clear that this surface is enriched in iron so one must expect an even more pronounced curve for iron than the one after deposition. This is not the case as shown in fig. 9 which means that the facets are mainly composed of iron.

Earlier it was observed that iron matches well with an original $\mathrm{Cu}(111)$ plane [2]. Also the angle of inclination $\alpha=35.2^{\circ}$ was observed regularly for iron planes with segregated elements - most recently $\mathrm{Sb}$ on $\mathrm{Fe}(110)$ [12] - and 
on tungsten (also bcc structure) planes. This suggests that bec metals grow according to (111) planes on fcc metals whenever an atomic distance is present at the fcc surface that matches those of a (110) bcc plane. Verification of this assumption is possible studying the growth of bcc metals on such fcc planes like (211) and (221).

The formation of two differently oriented iron crystallites explains the unusual change of $\delta \Delta$ during iron deposition. This change is basically due to scattering of the incident laser beam by a somehow irregular surface structure. Such a facetted surface may in this respect be compared to a surface roughened by $\mathrm{Ar}^{+}$sputtering. Albers et al. [13] have studied the influence of induced surface roughening on the ellipsometric parameters $\delta \Delta$ and $\delta \psi$ by sputtering for several hours on a silver single crystal. They found that $\delta \psi$ was negligibly influenced, but that $\delta \Delta$ could change by about $10^{\circ}$ after prolonged sputtering. So the extent of the variation of $\delta \Delta$ during deposition can be attributed to a "surface roughening", caused by facet formation.

When before deposition of iron the annealing time is short, less iron is observed near the surface layer than when the surface is annealed longer. Apparently iron is easier dissolved in copper in this case. Obviously there are more voids present which enable the migration of iron. The presence of voids was earlier discussed and their existence succesfully used in a model describing the deposition of nickel on copper [6].

As $x_{\mathrm{L}}$ is less than $x_{\mathrm{H}}$, again the most outer surface layer is enriched in copper [2], however this cannot be concluded from the sputter profile indicating that this enrichment is very small.

Since the total sputtering time to remove an equal amount of iron is three times larger for $\mathrm{Cu}(110)$ than for $\mathrm{Cu}(111)$ [2] one concludes that iron diffuses easicr through a more open plane. This parallels the behaviour of nickel in copper [6].

\subsection{Oxidation of $\mathrm{Cu}(1 / \mathrm{lO})-\mathrm{Fe}$}

The strange behaviour of $\delta \Delta$ upon oxygen exposure must be attributed to the distortion of iron facets. It has been shown that during the deposition of iron $\delta \Delta$ rises enormously due to the formation of $F e(110)$ facets. When oxygen is exposed it will cause the disappearance of the facets [5]. This results in a decrease of $\delta \Delta$, which can be much larger than the increase due to oxygen adsorption.

The reported $(2 \times 1)$ and $c(6 \times 2)$ LEED patterns are also observed during the oxidation of pure $\mathrm{Cu}(110)[3,4]$. Obviously the occupation of copper sites occurs unhindered by the presence of iron. There is no evidence of an iron oxide structure. However in a forthcoming paper [5] it will be shown that upon repeated reduction by $\mathrm{CO}$ and oxidation, an iron oxide develops from which a pattern originates that can be seen next to the $(2 \times 1)$ pattern. 
Fig. 7 shows the mobility of iron atoms in a crystal which is initially oxidized at $375 \mathrm{~K}$. As both the iron peaks $h_{47}$ and $h_{651}$ increase upon heating to $675 \mathrm{~K}$ and the oxygen peak remains constant, it can be concluded that iron has migrated to the surface an no diffusion of oxygen took place. From a subsequent oxidation at $675 \mathrm{~K}$ it follows that once iron is oxidized, it will again diffuse into the crystal, as the $651 \mathrm{eV}$ peak has diminished and the $47 \mathrm{eV}$ peak has disappeared again. The overall increase of all peaks is due to topographical effects, i.e. the recovery of an unfacetted surface [9]. The changes in peak heights after this treatment suggests that internal oxidation occurs because iron migrates to the surface and is bound to an adsorbed oxygen atom and next both diffuse into the crystal again; apparently oxygen alone is not able to diffuse.

The amount of iron present at the surface (as oxide) is limited and appears to be independent of the original amount of iron deposited. This can be seen from fig. 8, where the amount of iron at the surface is constant for $\delta \psi>0.3^{\circ}$ whereas initially (before oxidation) much higher iron mole fractions were present (cf. fig. 2). Only for initially iron-poor surfaces $\left(\delta \psi<0.3^{\circ}\right)$ this steady level cannot be reached. Since iron in excess of this constant mole fraction of $0.18-0.25$ can still be oxidized and diffuses away into the crystal, a surface coverage of $x_{\mathrm{H}}=0.18-0.25$ seems to be a thermodynamically determined limit.

The temperature dependence of the initial sticking coefficient of $\mathrm{Cu}(110)-\mathrm{Fe}$ alloys with an iron content corresponding to $x_{\mathrm{H}}(\mathrm{Fe})=0.25$ is shown in fig. 10 . Surprisingly $s(0)$ does not exceed 0.08 , whereas for pure iron $s(0)$ is unity [14] and for pure $\mathrm{Cu}(110)$ Habraken and Bootsma and several other authors $[3,15,16]$ have found a value of 0.17 . To examine this discrepancy we measured

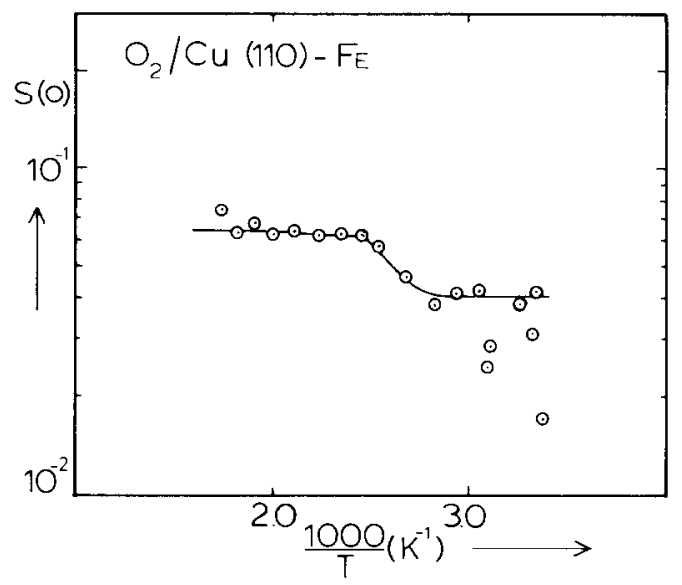

Fig. 10. Arrhenius plot of the initial sticking probability of oxygen on $\mathrm{Cu}(110)-\mathrm{Fe}$ with $x_{H}(\mathrm{Fe})=0.25$. The line is drawn according to a suggestion in the text. 
$s(0)$ for pure $\mathrm{Cu}(110)$. Confusingly we did not find $s(0)=0.17$, but $s(0)=$ $0.065 \pm 0.010$, independent of the temperature for $T<575 \mathrm{~K}$. There was, however, one striking difference between the measurements of Habraken et al. and ours, namely that they did not start at zero oxygen coverage while in our case we (accidently) did. To clarify this difference one must consider that we sputtered the $\mathrm{Cu}(110)-\mathrm{Fe}$ alloy until no iron and no oxygen $\left(\theta_{\mathrm{O}}<0.01\right)$ could be detected. As iron penetrates rather deep into the crystal, the latter was sputtered under more severe conditions ( $I \cong 4 \mu \mathrm{A} / \mathrm{cm}^{2}, T=725 \mathrm{~K}, 10 \mathrm{ks}$ ) than was commonly done by Habraken et al. To investigate whether this discrepancy was caused by this oxygen some extra experiments were done. When we performed the standard procedure for $\mathrm{Cu}(110)$ of sputtering ( $I=1.0$ $\mu \mathrm{A} / \mathrm{cm}^{2}, T=375 \mathrm{~K}, 3 \mathrm{ks}$ ) an oxidized iron-free crystal, indeed some oxygen was left $\left(\theta_{\mathrm{O}}=0.05\right)$ and now (after annealing) a $s(0)$ of $0.17 \pm 0.02$ was found. The sputtering of an oxidized $\mathrm{Cu}(110)$ crystal for $10 \mathrm{ks}$ at a current of 4 $\mu \mathrm{A} / \mathrm{cm}^{2}$ resulted in a surface free of oxygen and a $s(0)$ of 0.065 was measured again. In addition to these experiments several oxidations were performed after reduction by $\mathrm{CO}$ of an oxidized pure $\mathrm{Cu}(110)$ surface. After reduction some oxygen was still present at the surface $\left(\theta_{\mathrm{O}}=0.05\right)$ and again $s(0)=0.17$ \pm 0.01 was found.

The reproducibility of the experiments and the fact that they were performed in the same vacuum chamber prove the significance of the difference in sticking coefficient. The scatter of the sticking coefficient for the $\mathrm{Cu}(110)-\mathrm{Fe}$ system at low temperatures is not representative for this system with only pure Cu(110). Apparently a very small amount of oxygen cannot easily be removed neither by $\mathrm{CO}$ nor by sputtering and is responsible for a larger sticking coefficient.

Further support for our assumptions is delivered by Mesters et al. [17], who observed a $s(0)$ of about 0.07 both for $\mathrm{Cu}(110)$ and $\mathrm{Cu}(110)-\mathrm{Ni}$, and also an increased rate of adsorption of oxygen on $\mathrm{Cu}(110)-\mathrm{Ni}$ after adsorbing oxygen and reducing by carbon monoxide.

Fig. 11 shows the behaviour of the sticking coefficient $s(0)$ as a function of $x_{\mathbf{H}}(\mathrm{Fe})$ at $425 \mathrm{~K}$. At low iron fractions $s(0)$ is equal to 0.064 but suddenly at a rather critical value of $x_{\mathrm{H}}(\mathrm{Fe})=0.29 s(0)$ drops to a value of 0.040 and thereafter remains constant as far as experiments were performed. The complete picture of $s(0)$ versus temperature and iron fraction is somehow confusing. Comparing our numbers $(s(0)=0.04$ to 0.06$)$ with the sticking coefficient of oxygen on pure iron $(s(0)=1[14])$ a large difference is found. However, on pure iron the sticking coefficient quickly drops to $0.05 \pm 0.02$ when the oxygen coverage reaches a value of $\theta_{\mathrm{O}}=0.06$. This small amount of oxygen on pure iron represents an even smaller amount of oxygen when present in the same $\mathrm{Fe} / \mathrm{O}$ ratio on our copper-iron alloys. It is then more likely that, if oxygen adsorbs on iron sites, the value of $0.05 \pm 0.02$ would be measured in our system. This number is too close to the sticking coefficient of oxygen on pure 


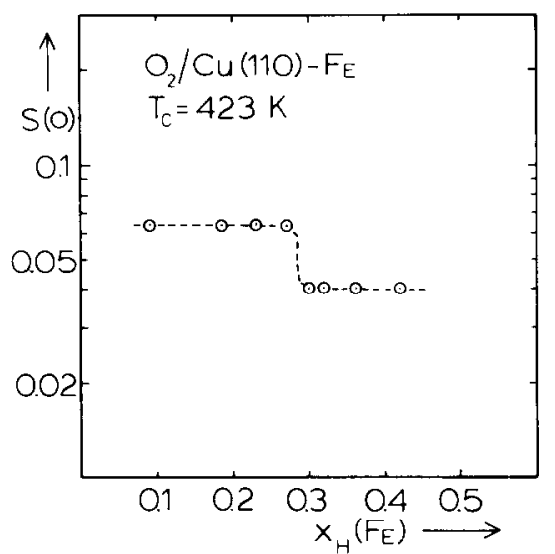

Fig. 11. Initial sticking probability of oxygen on $\mathrm{Cu}(110)-\mathrm{Fe}$ with different iron contents as a function of the iron mole fraction $x_{\mathrm{H}}(\mathrm{Fe})$ at $423 \mathrm{~K}$. The line is drawn to guide the eye.

copper, $s(0)=0.064$ as determined by us, to draw any conclusions about the observed behaviour of $s(0)$ in terms of copper and iron sites.

The drop of $s(0)$ at $x_{\mathrm{H}}(\mathrm{Fe})=0.29$ is strange. As the carbon contamination increases a little with the iron fraction one might argue that carbon is responsible for this drop. To investigate such a possibility, a crystal was prepared corresponding to $x_{\mathrm{H}}(\mathrm{Fe})=0.20$ and on purpose an identical amount of carbon was deposited by exposing it to $\mathrm{CO}$ at $300 \mathrm{~K}$ [18] as the amount of carbon present after deposition at $x_{\mathrm{H}}(\mathrm{Fe})=0.35$. Yet, still, $s(0)=0.064$ was measured. Thus carbon is not responsible for this drop. Also a sudden change in the adsorption kinetics does not occur. The curve in fig. 11 is strongly suggestive for a surface phase transition. Unfortunately no change in LEED pattern was observed when traversing this iron fraction of $x_{\mathrm{H}}(\mathrm{Fe})=0.29$.

Already during the initial stage of adsorption of oxygen iron becomes oxidized since a $44 \mathrm{eV}$ AES peak appears. However, a simultaneous oxidation of copper cannot be ruled out from the preceding discussion. On $\mathrm{Cu}(111)-\mathrm{Fe}$ it was observed that initially only iron becomes oxidized. It would be interesting to know if this also occurs on $\mathrm{Cu}(110)-\mathrm{Fe}$. Therefore, on purpose some oxygen $\left(\theta_{\mathrm{O}}=0.05\right)$ was left at the surface after oxidation, sputtering and annealing of pure $\mathrm{Cu}(110)$ and next iron was deposited. Again the sticking probability of $s(0)=0.065$ for oxygen at $423 \mathrm{~K}$ was found. Under these conditions $s(0)=0.17$ should have been found if oxygen had been left on copper sites. Since this is not the case we are forced to assume that oxygen was trapped by iron, when iron was deposited, leaving a copper surface entirely free of oxygen. So as adsorbed oxygen will move to iron sites, oxygen from the gas-phase will surely be adsorbed first by iron. Again also on this plane oxidation starts with iron. 


\section{References}

[1] F.C. Schouten, E.W. Kaleveld and G.A. Bootsma, Surface Sci. 63 (1977) 460.

[2] O.P. van Pruissen, E. Boellaard, O.L.J. Gijzeman and J.W. Geus, Appl. Surface Sci. 27 (1986) 1.

[3] F.H.P.M. Habraken and G.A. Bootsma, Surface Sci. 87 (1979) 333.

[4] F.H.P.M. Habraken, G.A. Bootsma, P. Hofmann, S. Hachicha and A.M. Bradshaw, Surface Sci. 88 (1979) 285.

[5] O.P. van Pruissen, O.L.J. Gijzeman and J.W. Geus, to be published.

[6] C.M.A.M. Mesters, G. Wermer, O.L.J. Gijzeman and J.W. Geus, Surface Sci. 135 (1983) 396.

[7] G. Salje and M. Feller-Kniepmeier, J. Appl. Phys. 49 (1978) 229.

[8] D.L. Williamson and M. Ellid, J. Phys. (Paris) 40 (1979) C2-601.

[9] O.P. van Pruissen, M.M.M. Dings, E. Boellaard, O.L.J. Gijzeman and J.W. Geus, Appl. Surface Sci. 27 (1986) 24.

[10] C.W. Tucker, J. Appl. Phys. 38 (1967) 1988.

[11] G. Ertl and J. Küppers, Low Energy Electrons and Surface Chemistry (Verlag Chemie, Weinheim, 1974) pp. 129ff.

[12] M. Rüsenberg and H. Viefhaus, Surface Sci. (1986) 615.

[13] H. Albers, J.M.M. Droog and G.A. Bootsma, Surface Sci. 64 (1977) 1.

[14] T. Miyano, Y. Sakisaka, T. Komeda and M. Onchi, Surface Sci. 169 (1986) 197.

[15] I.E. Wachs and R.J. Madix, J. Catalysis 53 (1978) 208.

[16] T.M. Hupkens and J.M. Fluit, Surface Sci. 143 (1984) 267.

[17] C.M.A.M. Mesters, A.F.H. Wielers, O.L.J. Gijzeman, G.A. Bootsma and J.W. Geus, Surface Sci. 117 (1982) 605.

[18] O.L.J. Gijzeman, T.J. Vink, O.P. van Pruissen and J.W. Geus, J. Vacuum Sci. Technol., accepted for publication. 